\title{
Perbandingan Tanggapan Kardiovaskular dan Kemudahan Intubasi dengan Menggunakan Laringoskop McCoy dan Macintosh pada Ras Melayu di Indonesia
}

\author{
Riyadh Firdaus $^{1^{*}}$, Aries Perdana ${ }^{1}$, Nur'aini Alamanda ${ }^{1}$ \\ 1. Departemen Anestesiologi dan Terapi Intensif, Fakultas Kedokteran Universitas Indonesia, \\ RSUPN Dr. Cipto Mangunkusumo, Jakarta, Indonesia
}

\begin{abstract}
ABSTRAK
Latar belakang: Intubasi endotrakeal dan laringoskopi direk merupakan standar emas dalam tatalaksana jalan nafas baik pada keadaan gawat darurat ataupun tidak. Peningkatan tanggapan kardiovaskular karena rangsangan simpatis merupakan komplikasi yang paling sering terjadi saat intubasi. Tanggapan kardiovaskular dapat berbahaya bagi pasien-pasien yang berisiko, terutama yang memiliki masalah gangguan jantung. Metode pemilihan bilah merupakan salah satu teknik non farmakologi yang digunakan untuk mengurangi tanggapan kardiovaskular yang timbul akibat intubasi. Penelitian ini bertujuan untuk membandingkan tanggapan kardiovaskular dan kemudahan intubasi antara laringoskop McCoy dan Macintosh.

Metode: Uji klinis acak tersamar tunggal, dengan 78 pasien yang akan menjalani anestesi umum dengan intubasi endotrakeal dan dibagi ke dalam 2 kelompok, yaitu McCoy dan Macintosh. Kriteria inklusi adalah pasien usia 18-65 tahun dengan status fisik ASA 1 dan ASA 2 tanpa penyulit jalan napas. Midazolam 0,05 mg/kgBB dan fentanyl $2 \mathrm{mcg} / \mathrm{kgBB}$ diberikan sebagai agen koinduksi. Induksi anestesi menggunakan propofol $2 \mathrm{mg} / \mathrm{kgBB}$, dilanjutkan dengan pemberian rocuronium 0,6 $\mathrm{mg} /$ kgBB setelah dipastikan hilangnya refleks bulu mata. Tanggapan kardiovaskular yang diukur (tekanan sistolik, diastolik, tekanan arteri rerata, dan laju denyut nadi). Intubasi dikatakan mudah bila dilakukan dalam waktu kurang dari 10 menit dan tidak lebih dari 3 kali percobaan.

Hasil: Pada menit pertama pasca-intubasi, tekanan darah sistolik, diastolik, dan laju denyut nadi kelompok McCoy lebih tinggi dibandingkan Macintosh, dengan perbedaan tekanan sistolik $-2,38$ $(-9,93-5,16) \mathrm{mmHg}$, tekanan diastolik -1,07 (-7,313-5,15 95\% IK) mmHg, laju denyut nadi 2,79(-2,69$8,28)$ kali per menit. Pada menit ke-3 pasca intubasi, tekanan sistolik, diastolik, tekanan arteri rerata, dan laju denyut nadi kelompok McCoy tetap lebih tinggi dibandingkan dengan Macintosh, dengan perbedaan tekanan sistolik $-1,23(-8,51-6,05) \mathrm{mmHg}$, tekanan diastolik $-0,97(-6,69-4,75) \mathrm{mmHg}$, tekanan arteri rerata $-0,65(-6,27-4,97) \mathrm{mmHg}$, dan laju denyut nadi $0,89(-3,99-5,78)$ kali per menit. Kesimpulan: Intubasi dengan laringoskop McCoy tidak mampu menekan tanggapan kardiovaskular yang timbul akibat rangsang nyeri dan stimulasi simpatis.
\end{abstract}

Kata kunci : Intubasi, tanggapan kardiovaskular, laringoskop, laringoskopi 


\title{
Comparison of Cardiovascular Response and Intubation Ease between McCoy and Macintosh Laryngoscopy in Malay Race of Indonesia
}

\author{
Riyadh Firdaus $^{1^{*}}$, Aries Perdana ${ }^{1}$, Nur'aini Alamanda ${ }^{1}$
}

1. Departement of Anesthesiology and IntensifCare, Faculty of Medicine, Universitas Indonesia, Dr. Cipto Mangunkusumo National General Hospital, Jakarta, Indonesia

\begin{abstract}
Background: Endotracheal intubation with direct laryngoscopy is the gold standard of airway management. Increasing cardiovascular response due to sympathetic stimulation is the most common complication during intubation. This cardiovascular response can be dangerous for patients at risk, especially those who have cardiac and cerebrovascular disorders. The blade selection method is a non-pharmacological technique that can be employed to reduce cardiovascular response of intubation. This study aims to compare the cardiovascular response and intubation ease between McCoy and Macintosh laryngoscopy.

Method: This is a single blind randomized clinical study on 78 adult patients undergoing endotracheal intubation for elective general anesthesia. Subjects are divided into 2 groups: McCoy and Macintosh. The inclusion criteria were age 18-65 years old with physical status ASA 1 and ASA 2 without airway difficulty. All patients received the same anesthesia regiment of midazolam 0,05 $\mathrm{mg} / \mathrm{kg}$, fentanyl 2 $\mathrm{mcg} / \mathrm{kg}$, propofol $2 \mathrm{mg} / \mathrm{kg}$, and rocuronium $0.6 \mathrm{mg} / \mathrm{kg}$. After loss of eyelash reflex, laryngoscopy was performed Cardiovascular response measured includes systolic pressure, diastolic pressure, mean arterial pressure, and heart rate. Intubation is considered to be easy if it is done in less than 10 minutes and not more than 3 trials.

Results: In the first minute after intubation, systolic, diastolic blood pressure, and heart rate in McCoy group were higher than Macintosh group, with a difference in systolic pressure of -2.38 (-9.93-5.16) $\mathrm{mmHg}$, diastolic pressure -1.07 (-7.313-5.15 95\% Cl) mmHg, pulse rate 2.79 (-2.69-8.28) beats per minute. In the $3 r d$ minute after intubation, systolic pressure, diastolic pressure, mean arterial pressure, and heart rate of McCoy group remained higher compared to the Macintosh, with a difference of systolic pressure $-1.23(-8.51-6.05) \mathrm{mmHg}$, pressure diastolic $-0.97(-6.69-4.75) \mathrm{mmHg}$, mean arterial pressure -0.65 9-6.27-4.97) $\mathrm{mmHg}$, and pulse rate 0.89 (-3.99-5.78) beats per minute
\end{abstract}

Conclusion: Intubation with McCoy's laryngoscope was unable to suppress cardiovascular response arising from pain and sympathetic stimulation.

Keywords: Intubation, cardiovascular response, laryngoscope, laryngoscopy 


\section{PENDAHULUAN}

Ketidakmampuan dalam tatalaksana sulit jalan nafas berperan dalam 30\% dari total kematian jumlah pasien yang menjalani pembiusan. Berbagai macam metode telah digunakan untuk mengamankan jalan nafas, seperti orotrakeal, nasotrakeal, dan trakeostomi. ${ }^{1}$ Laringoskopi, intubasi endotrakeal, dan manipulasi jalan nafas yang lain dapat menyebabkan rangsangan berbahaya yang bisa mencetuskan perubahan tiba-tiba pada sistem fisiologi kardiovaskular, terutama respon refleks. Komplikasi serius dapat terjadi pada pasien-pasien yang mempunyai penyakit penyerta seperti penyakit jantung terutama pada penyakit jantung koroner. Pada pasien dengan coronary arterial disease (CAD) atau pasien dengan risiko CAD, kematian sel-sel miokard bisa terjadi selama selama rangkaian induksi dan intubasi. ${ }^{2}$

Pada penelitian perbandingan tanggapan kardiovaskular dengan menggunakan laringoskop Macintosh dan McCoy antara jalan nafas mudah dengan jalan nafas diperkirakan sulit yang dilakukan oleh Zia Arshad, et al, didapatkan perbedaan tekanan diastolik secara signifikan bermakna ( $p=0,009)$ lebih tinggi pada penggunaan laringoskop Macintosh dibandingkan McCoy pada jalan nafas yang diperkirakan sulit, sedangkan frekuensi nadi secara signifikan naik ( $p=0,0001)$ pada laringoskop Macintosh dibandingkan McCoy pada pasien dengan jalan nafas baik maupun yang diperkirakan sulit. ${ }^{3}$ Lamanya waktu yang dibutuhkan untuk laringoskopi dan intubasi trakea, juga mempunyai efek signifikan terhadap respon tekanan jalan nafas selama 60 detik laringoskopi. ${ }^{3}$ Pada penelitian perbandingan waktu yang dibutuhkan untuk intubasi antara McCoy dan Macintosh yang dilakukan oleh Neerja Bharti et al menunjukkan bahwa 91\% pasien berhasil terintubasi pada satu kali percobaan dengan menggunakan McCoy dan $84 \%$ pada Macintosh. ${ }^{4}$ Literatur-literatur anestesi lebih banyak membahas metodemetode farmakologi dan pengaruhnya terhadap sistem kardiovaskular dibandingkan dengan literatur yang berkaitan dengan metode non farmakologi, khususnya model bilah, masih terbatas. Berdasarkan hal tersebut, peneliti ingin membandingkan tanggapan kardiovaskular dan kemudahan intubasi pada laringoskop Macintosh dan McCoy.

\section{METODE PENELITIAN}

Sampel penelitian adalah pasien dewasa yang menjalani pembiusan umum dengan intubasi endotrakeal pada periode Desember 2018 Februari 2019 di kamar operasi Rumah Sakit Cipto Mangunkusumo. Penentuan perlakuan terhadap subjek dilakukan secara acak dengan metode 'single blind dan total subjek mencapai 78.

Kriteria inklusi penelitian ini adalah 18-65 tahun dengan index massa tubuh $18,5-30 \mathrm{~kg} /$ $\mathrm{m}^{2}$ dan status fisik ASA 1 dan ASA 2 tanpa penyulit jalan nafas. Kriteria eksklusi penelitian ini adalah kehamilan, riwayat penyakit jantung infark miokard, gagal jantung kiri atau kanan, interval P-R > 0,24 detik, blok jantung derajat 2 atau 3, menggunakan alat pacu jantung, riwayat penyakit serebrovaskular, takikardia atau bradikardia, sedang mengkonsumsi obat anti aritmia, penyekat beta adrenoreseptor, atau stimulasi jantung, terdapat dugaan kesulitan jalan nafas, baik ventilasi yang dinilai dengan MOANS, maupun intubasi yang dinilai dengan LEMONS, dan pasien dengan peningkatan tekanan intrakranial. Kriteria pengeluaran adalah pada pasien yang mengalami desaturasi atau kegawatdaruratan lainnya, tidak mencapai Cormack-Lehane 1 atau 2 pada upaya laringoskopi pertama dengan laringoskop McCoy atau dengan laringoskop Macintosh (maksimal 60 detik), konversi dari anestesi umum ke anestesi regional sebelum intubasi, dan anestesi umum yang merupakan konversi dari anestesi regional. Midazolam 0,05mg/kgBB dan fentanyl $2 \mathrm{mcg} /$ kgBB diberikan sebagai agen koinduksi.

Cara pengambilan sampel dengan consecutive sampel. Pada penelitian ini pengambilan sampel dilakukan menggunakan program komputer (www.random.org). Sampel terbagi menjadi dua kelompok yaitu laringoskop Macintosh dan laringoskop McCoy. Pada randomisasi sederhana ini setiap pasien mempunyai kesempatan yang sama untuk memperoleh perlakuan A (laringoskop Macintosh) atau perlakuan B (laringoskop McCoy). Pada penelitian ini metode pengambilan sampel menggunakan program 
komputer (www.random.org). Intubasi dilakukan oleh PPDS anestesiologi tahap pembekalan dan tahap magang yang belum terbiasa melakukan intubasi dengan laringoskop McCoy.

Subjek penelitian dipilih berdasarkan kriteria inklusi yang didapatkan dari anamnesis, pemeriksaan fisik dan pemeriksaan penunjang. Peserta penelitian dijelaskan mengenai penelitian dan tujuannya, serta diminta untuk menandatangani formulir persetujuan sebagai dokumentasi. Semua data yang dikumpulkan telah mendapatkan persetujuan dari komite etik dan persetujuan tertulis dari pasien. Pasien yang yang tidak ingin berpartisipasi dalam penelitian akan menjalani prosedur sesuai standard rumah sakit.

Di dalam ruang operasi, pada pasien dilakukan pemasangan alat pemantauan tekanan darah, EKG, dan pulse oksimeter dan pemberian cairan $20 \mathrm{cc} / \mathrm{kgBB}$. Kemudian dilakukan pengukuran pertama, tekanan darah sistolik, diastolik, tekanan arteri rerata, dan frekuensi nadi. Bila pada pengukuran pertama didapatkan tekanan darah sistolik > $140 \mathrm{mmHg}$, diastolik >90 mm Hg, laju nadi $>100$ kali/menit, pasien akan diberikan midazolam 0,05 mg/kgBB dan fentanyl $1 \mathrm{mcg} /$ kgBB intravena terlebih dahulu dan ditunggu selama 2 menit. Apabila didapatkan tekanan darah sistolik $>140 \mathrm{mmHg}$, diastolik $>90 \mathrm{mmHg}$, frekuensi nadi $<60$ kali/menit atau $>100$ kali/ menit, 2 menit setelah pemberian midazolam dan fentanyl, maka pasien dikeluarkan dari penelitian.

Apabila 2 menit setelah diberikan midazolam dan fentanyl didapatkan tekanan sistolik $<140$ $\mathrm{mmHg}$, diastolik $<90 \mathrm{mmHg}$, frekuensi nadi 60-100 kali/menit, maka dilanjutkan dengan pemberian fentanyl $1 \mathrm{mcg} / \mathrm{kgBB}$ dan rocuronium $0,6 \mathrm{mg} / \mathrm{kgBB}$, dan ditunggu selama 3 menit. Kemudian kembali dilakukan pengukuran tekanan darah sistolik, diastolik, tekanan arteri rerata, dan frekuensi nadi yang kedua. Randomisasi dilakukan untuk menentukan laringoskop yang akan digunakan pada pasien. Sebelum laringoskopi, pasien diberikan bantuan ventilasi dengan volume tidal $6-8 \mathrm{ml} / \mathrm{kgBB}$ dan laju pernafasan 12-14 kali/menit. Laringsokopi dilakukan menggunakan laringoskop Macintosh atau McCoy hingga visualisasi laring mencapai nilai Cormack-Lehane derajat 1 atau 2. Jika dibutuhkan waktu lebih dari 10 menit pada laringoskopi untuk mencapai Cormack-Lehane derajat 1 atau 2, maka pasien dikeluarkan dari penelitian karena masuk kriteria sulit jalan nafas, dan ditatalaksana sesuai algoritma American Society of Anesthesiology (ASA). Jika pada saat laringoskopi didapatkan CormackLehane derajat 1 atau 2 kurang dari 10 menit, maka dilakukan intubasi dengan selang endotrakeal no. 7 atau 7,5. Tekanan darah sistolik, diastolik, tekanan arteri rerata, dan frekuensi nadi diukur pada 1 menit dan 3 menit setelah laringoskopi. Kemudahan intubasi akan ditetapkan berdasarkan waktu yang dibutuhkan untuk laringoskopi (< 10 menit) dan upaya yang dibutuhkan ( $>3$ kali), dimana waktu dihitung mulai pada saat bilah laringoskop masuk ke dalam mulut sampai intubasi dikatakan berhasil. Jika selama tindakan terjadi kegawatdaruratan maka akan ditatalaksana sesuai algoritma ALS dan BLS yang berlaku dan pasien akan dikeluarkan dari sampel penelitian.

Data akan dianalisis dengan program adalah Statistical Package for Social Scientist (SPSS) versi 20. Data numerik akan dianalisa dengan menggunakan uji T tidak berpasangan jika data terdistribusi normal, atau uji Mann-Whitney jika data tidak terdistribusi normal. Data nonparametrik akan dianalisa dengan Chi-square atau Fisher bila expected count $<5$ lebih dari $20 \%$. Hasil analisis dinilai bermakna secara statistik untuk nilai kemaknaan (nilai p) $<0,05$ dengan confidence interval 95\%.

\section{HASIL}

Total 78 subjek terbagi menjadi 2 kelompok, kelompok yang menggunakan Laringoskop McCoy dan kelompok yang menggunakan Laringoskop Macintosh. Selama penelitian dilakukan, didapatkan 1 subjek menolak untuk ikut serta dalam penelitian dan 4 subjek yang dikeluarkan dari penelitian.

Dari tabel 1 terlihat bahwa sebaran demografis subjek penelitian di tiap variabel relatif sama pada tiap kelompok. Data perbandingan selisih variabel kardiovaskular antar kedua kelompok pasca-intubasi, terlihat pada tabel 2, menunjukkan tidak terdapat perbedaan bermakna semua parameter kardiovaskular. 
Perbedaan bermakna tidak didapatkan pada tekanan darah sistolik, diastolik, tekanan arteri rerata, dan laju denyut nadi antar kedua kelompok pada menit ke-1 dan menit ke-3 pasca intubasi $(p>0,05)$. Hasil uji Mann Whitney pada variabel upaya mendapati bahwa kelompok McCoy mempunyai peringkat yang lebih tinggi dibandingkan dengan kelompok Macintosh $(42,01$ vs 36,99$)$.

Tabel 1. Karakteristik subjek penelitian antar kelompok

\begin{tabular}{|c|c|c|}
\hline Variabel & Macintosh (n=39) & McCoy $(n=39)$ \\
\hline \multicolumn{3}{|l|}{ Jenis Kelamin ${ }^{a}$} \\
\hline Laki-laki & $20(51,3 \%)$ & $24(61,5 \%)$ \\
\hline Perempuan & $19(48,7 \%)$ & $15(38,5 \%)$ \\
\hline Umur (tahun) ${ }^{\mathrm{b}}$ & $32(18-61)$ & $34(18-64)$ \\
\hline Berat Badan $(\mathrm{kg})^{c}$ & $59,46 \pm 13,64$ & $60,64 \pm 11,38$ \\
\hline Tinggi Badan $(\mathrm{cm})^{\mathrm{b}}$ & $160(143-184)$ & $162(136-178)$ \\
\hline Indeks Masa Tubuh (m2/kg) & $22,41 \pm 4,06$ & $22,93 \pm 3,29$ \\
\hline \multicolumn{3}{|l|}{ Status Fisik ${ }^{\mathrm{a}}$} \\
\hline ASA 1 & $23(59)$ & $21(53,8)$ \\
\hline ASA 2 & $16(41)$ & $18(46,2)$ \\
\hline TDS sebelum induksi $(\mathrm{mmHg})^{\mathrm{b}}$ & $129(110-139)$ & $123(103-138)$ \\
\hline TDD sebelum induksi $(\mathrm{mmHg})^{c}$ & $79,07 \pm 8,94$ & $77,94 \pm 8,65$ \\
\hline MAP sebelum induksi $(\mathrm{mmHg})^{c}$ & $94,83 \pm 7,52$ & $92,98 \pm 8,32$ \\
\hline Laju nadi sebelum induksi (kali/menit) ${ }^{\mathrm{b}}$ & $80(60-100)$ & $76(60-100)$ \\
\hline
\end{tabular}

Tabel 2. Perbandingan selisih perubahan tanggapan kardiovaskular pasca intubasi antar kedua kelompok

\begin{tabular}{|c|c|c|c|c|}
\hline Variabel Kardiovaskular & Macintosh (N=39) & McCoy (N=39) & $\mathbf{p}$ & Perbedaan (95\% IK) \\
\hline \multicolumn{5}{|l|}{ Sistolik (mmHg) } \\
\hline 1 menit post intubasi & $30,33 \pm 17,14$ & $32,71 \pm 16,33$ & $0,531 a$ & $-2,38(-9,93-5,16)$ \\
\hline 3 menit post intubasi & $21,56 \pm 15,12$ & $22,79 \pm 17,11$ & $0,737 a$ & $-1,23(-8,51-6,05)$ \\
\hline \multicolumn{5}{|l|}{ Diastolik (mmHg) } \\
\hline 1 menit post intubasi & $21,33 \pm 14,22$ & $22,41 \pm 13,36$ & $0,732 a$ & $-1,07(-7,313-5,15)$ \\
\hline 3 menit post intubasi & $15,12 \pm 11,8$ & $16,10 \pm 13,50$ & $0,736 a$ & $-0,97(-6,69-4,75)$ \\
\hline \multicolumn{5}{|l|}{ Tekanan arteri rerata $(\mathrm{mmHg})$} \\
\hline 1 menit post intubasi & $26(-80,66-49,67)^{*}$ & $25(0-44) *$ & $0.857 b$ & \\
\hline 3 menit post intubasi & $17,40 \pm 11,80$ & $18,05 \pm 13,11$ & $0,818 a$ & $-0,65(-6,27-4,97)$ \\
\hline \multicolumn{5}{|l|}{ Nadi (kali/menit) } \\
\hline 1 menit post intubasi & $20,82 \pm 13,2$ & $22,79 \pm 17,11$ & $0,314 a$ & $2,79(-2,69-8,28)$ \\
\hline 3 menit post intubasi & $14,89 \pm 10,40$ & $14,00 \pm 11,27$ & 0,716a & $0,89(-3,99-5,78)$ \\
\hline
\end{tabular}


Tabel 3. Hasil Analisis Kemudahan Intubasi antar Kelompok

\begin{tabular}{llll}
\hline Variabel & \multicolumn{3}{c}{ Perbedaan kelompok } \\
\cline { 2 - 4 } & Macintosh (N=39) & McCoy (N=39) & $\mathbf{p}^{\mathrm{a}}$ \\
\hline Waktu & & & \\
$<10$ menit & $39(100 \%)$ & $0(100 \%)$ & - \\
$>10$ menit & $0(0 \%)$ & $0(0 \%)$ & 0,048 \\
\hline Upaya & & $33(84,6 \%)$ & \\
1 kali & $38(97,4 \%)$ & $5(12,8 \%)$ & \\
2 kali & $1(2,6 \%)$ & $1(2,6 \%)$ & \\
4 kali & $0(0 \%)$ & & \\
TUji tidak berpasangan. &
\end{tabular}

\section{PEMBAHASAN}

Pada variabel umur (tabel 1), median umur pada kelompok Macintosh adalah 32 tahun dan median umur pada kelompok McCoy adalah 34 tahun. Intubasi yang sulit dilakukan, dilaporkan mencapai $15 \%$ pada pasien obesitas dibandingkan pada orang ramping yang hanya 2-6\%. Obesitas memberi potensi penyulit tambahan pada pengelolaan jalan napas selama ventilasi, intubasi, dan atau keduanya. ${ }^{5}$ Obesitas didefinisikan sebagai lemak berlebih di tubuh, World Health Organization (WHO)mendefinisikan obesitas sebagai indeks massa tubuh (IMT) $\geq 30$ $\mathrm{kg} / \mathrm{m}^{2}$. Obesitas juga mengurangi cadangan oksigen, sehingga waktu yang tersedia untuk melakukan manipulasi jalan nafas menurun. Pada penelitian-penelitian terbaru, $16,3 \%$ pasien obesitas sulit di ventilasi menggunakan sungkup wajah, hal ini dikarenakan terdapat cadangan lemak di struktur servikal. ${ }^{6}$ Berdasarkan data di atas, indeks masa tubuh (IMT) peserta penelitian (Tabel 1) dibatasi pada rentang normal untuk menghindari kemungkinan kesulitan ventilasi dan intubasi yang disebabkan karena masa tubuh yang di bawah normal maupun di atas normal. Status fisik ASA (Tabel 1) juga dibatasi pada ASA 1 atau 2 untuk mengurangi variabel perancu pra-operatif seperti hipovolemik, pengaruh obat-obatan kardiovaskular, aritmia dan kelainan kardiovaskular lain. Semua sampel pada penelitian ini mendapatkan perlakuan yang sama, yaitu pembiusan umum dengan obat anestesi intravena dengan agen koinduksi dan induksi berturut-turut yaitu midazolam dan fentanyl, serta propofol.

Penelitian ini menilai tanggapan kardiovaskular yang terdiri dari tekanan darah sistolik, diastolik, tekanan arteri rerata, dan laju nadi (Tabel 2). Penilaian kardiovaskular pertama dilakukan saat pasien sudah berbaring di meja operasi, setelah mendapatkan loading cairan 10-20 cc/kgBB dan pemberian midazolam dan fentanyl sebagai agen koinduksi. Pada tabel 1 terlihat tanggapan kardiovaskular pada kedua kelompok tidak berbeda. Hal ini menunjukkan bahwa faktorfaktor perancu kardiovaskular saat pra induksi bisa dieliminasi dengan kriteria penerimaan dan penolakan. Setelah induksi anestesi, dilakukan pengukuran tekanan darah sistolik, diastolik, tekanan arteri rerata, dan frekuensi nadi. Parameter kardiovaskular pada kedua kelompok mengalami penurunan bermakna dibandingkan sebelum induksi. Hal ini bisa disebabkan karena pemberian cairan 10-20 cc/kgBB sebelum dilakukan induksi anestesi. Pemberian cairan bertujuan untuk mempertahankan atau mengembalikan segera keefektifan volume sirkulasi darah selama masa perioperatif. Terapi cairan merupakan lini pertama dalam menopang hemodinamik karena keefektifan sirkulasi volume darah yang dapat menurun seiring dilakukannya induksi. Pada pasienpasien operasi, beberapa faktor termasuk puasa preoperatif, persiapan pengosongan usus, agenagen anestesi, dan ventilasi tekanan positif, semuanya berkontribusi untuk menurunkan 
volume darah sirkulasi. $^{7}$

Rangsangan utama yang menyebabkan perubahan hemodinamik selama laringoskopi dan intubasi adalah tekanan bilah laringoskop pada bagian dasar lidah selama pengangkatan epiglotis. $^{8}$ Laringoskop McCoy mempunyai engsel pada ujungnya untuk menghindari menggunakan kekuatan pada saat mengangkat vallecula. ${ }^{8,9}$ Perbandingan respon kardiovaskular 1 menit dan 3 menit setelah intubasi pada kedua kelompok mendapatkan hasil yang tidak bermakna (Tabel 2). Peningkatan tanggapan kardiovaskular 1 menit dan 3 menit setelah intubasi yang lebih tinggi pada kelompok laringoskop McCoy (Tabel 2) dapat disebabkan oleh tidak dilakukannya evaluasi kedalaman mengenai pencapaian relaksasi otot setelah pemberian pelumpuh otot dan pelaku intubasi yang belum terbiasa menggunakan laringoskop McCoy. Hasil sebaliknya terlihat pada penelitian yang dilakukan oleh Hiteshi Aggarwal dkk yang juga membandingkan respons kardiovaskular dengan menggunakan Macintosh, McCoy, dan video laringoskop. Pada penelitian ini pelaku intubasi adalah dokter-dokter anestesi yang telah mengenal dan terlatih menggunakan Macintosh, McCoy, dan video laringoskop. ${ }^{10}$ Hasil penelitiannya menunjukkan bahwa peningkatan respon kardiovaskular akibat intubasi dengan menggunakan McCoy paling rendah dibandingkan dengan Macintosh dan video laringoskop, dimana kenaikan tekanan sistolik akibat intubasi dengan Macintosh 12,2\%, dengan McCoy 5,18\%, dan video laringoskop $13,4 \%$. Tekanan diastolik akibat intubasi dengan Macintosh 13,66\%, McCoy 6,88\%, dan video laringoskop 14,55\%, untuk peningkatan laju nadi juga didapatkan hasil yang rendah pada penggunaan McCoy (6,26\%), dibandingkan Macintosh (14,12\%), dan video laringoskop $(19,45 \%))^{10}$

Operator laringoskopi pada penelitian ini memegang peranan penting, hal ini terlihat pada tabel 3, dimana terdapat perbedaan bermakna $(p<0,05)$ antara kelompok laringoskop Macintosh dan McCoy. Hasil penelitian kami menunjukan bahwa kelompok Macintosh lebih mudah digunakan dibandingkan dengan McCoy (tabel 3). Hal ini disebabkan operator intubasi, yang mana adalah peserta PPDS tahap pembekalan dan magang. Selain itu, operator juga lebih terbiasa menggunakan Macintosh dan jarang menggunakan McCoy untuk laringoskopi. Berbeda dengan penelitian yang dilakukan oleh Manali Nadkarni dkk mengenai perbandingan di antara ketiga laringoskop yaitu Macintosh, McCoy, dan Miller dengan operator intubasi seorang anestesi berpengalaman, dengan masa pengalaman $2-5$ tahun. ${ }^{1}$ Pada penelitian ini didapatkan pula bahwa intubasi dengan menggunakan laringoskop McCoy lebih mudah dilakukan dibandingkan dengan Macintosh. ${ }^{1}$

Posisi sniffing merupakan posisi yang secara umum diterima sebagai posisi terbaik untuk laringoskopi langsung, dimana posisi ini terbentuk dari ekstensi kepala pada titik atlantooksipital dan elevasi oksiput. Pada penelitian yang dilakukan Ahmet Yildirim dkk tentang perbandingan laringoskopi intubasi dengan menggunakan Macintosh, McCoy, dan C-MAC (dengan bilah $\mathrm{D}$ ) oleh tenaga medis (dengan kriteria tenaga medis yang aktif di pelayanan ambulan minimal 2 tahun) pada manekin didapatkan bahwa angka kemudahan intubasi dengan McCoy lebih tinggi dibandingkan Macintosh pada posisi sniffing. ${ }^{11}$ Pada penelitian kami, pelaku intubasi tidak terbiasa dengan posisi sniffing, sehingga memerlukan usaha yang lebih banyak pada intubasi dengan laringoskop McCoy dibandingkan dengan Macintosh.

Penelitian ini memiliki kelemahan, yaitu tidak menggunakan metode pengukuran dengan Train of Four (TOF) untuk menilai apakah sudah terjadi relaksasi otot setelah pemberian pelumpuh otot, pelaku intubasi pada penelitian ini adalah PPDS anestesiologi tahap pembekalan dan tahap magang dan belum terbiasa melakukan intubasi dengan laringoskop McCoy, sedangkan penelitian-penelitian di luar negeri tentang perbandingan tanggapan kardiovaskular akibat intubasi dengan Macintosh dan McCoy, pelakunya adalah seorang dokter anestesi dengan pengalaman yang tinggi. Penelitian ini dapat dijadikan dasar dalam melakukan penelitian mengenai perbandingan prosedur laringoskopi menggunakan laringoskop yang berbeda-beda. Perlunya penggunaan TOF dan operator yang biasa sangat dibutuhkan dalam melakukan penelitian terkait. 


\section{KESIMPULAN}

Tidak terdapat perbedaan antara penggunaan laringoskop Macintosh maupun McCoy dalam menekan tanggapan kardiovaskular dalam prosedur intubasi.

\section{DAFTAR PUSTAKA}

1. Nadkarni DM, Patel DRD, Behera DP, Walzade DA. Comparison of Macintosh, McCoy and Miller Laryngoscope Blades for Intubation- A Prospective Randomised Study. IOSR J Dent Med Sci. 2016;15(08):85-91.

2. Sabry, Shaarawy SS, Ellakany MH, Elmasry AA. Comparison between C-MAC D-blade and McCoy laryngoscopes in intubating patients during cervical immobilization. Res Opin Anesth Intensive Care. 2016;3(3):122.

3. Arshad Z, Abbas H, Bogra J. Comparison of Laryngoscopic View and Hemodynamic Changes with Flexitip McCoy and Macintosh Laryngoscope Blade in Predicted Easy and Difficult Airway. Open J Anesthesiol. 2013;3(5):278-82.

4. Bharti, Arora S, Panda NB. A comparison of McCoy, TruView, and Macintosh laryngoscopes for tracheal intubation in patients with immobilized cervical spine. Saudi J Anaesth. 2014;8(2):188.

5. Siddiqui N, Katznelson R, Friedman. Heart rate/blood pressure response and airway morbidity following tracheal intubation with direct laryngoscopy, GlideScope and
Trachlight: a randomized control trial. Eur J Anaesthesiol. 2009;26(9):740-5.

6. Saasouh W, Laffey K, Turan A, et al. Degree of obesity is not associated with more than one intubation attempt: a large centre experience. Br J Anesth. 2018;120:901-903.

7. Navarro LHC, Bloomstone JA, Auler JOC, et al. Perioperative fluid therapy: a statement from the international Fluid Optimization Group. Perioper Med 2015 41. 2015;4(1):120.

8. Haidry MA, Khan FA. Comparison of hemodynamic response to tracheal intubation with Macintosh and McCoy laryngoscopes. J Anaesthesiol Clin Pharmacol. 2013;29(2):196-9.

9. Gill N, Purohit S, Kalra P, Lall T, Khare A. Comparison of hemodynamic responses to intubation: Flexible fiberoptic bronchoscope versus McCoy laryngoscope in presence of rigid cervical collar simulating cervical immobilization for traumatic cervical spine. Anesth Essays Res. 2015;9(3):337.

10. Aggarwal H, Kaur S, Baghla N, Kaur S. Hemodynamic Response to Orotracheal Intubation: Comparison between Macintosh, McCoy, and C-MAC Video Laryngoscope. Anesth Essays Res. 2019;13(2):308.

11. Yildirim A, Kiraz HA, Ağaoğlu I, Akdur O. Comparison of Macintosh, McCoy and C-MAC D-Blade video laryngoscope intubation by prehospital emergency health workers: a simulation study. Intern Emerg Med. 2017;12(1):91-7. 